DOI: 10.20472/EFC.2017.007.019

PAVEL POTUZAK

University of Economics, Prague, Czech Republic

\title{
ZERO TIME PREFERENCE AND ETERNAL POSTPONEMENT OF CONSUMPTION
}

\begin{abstract}
:
Ludwig von Mises in his magnum opus Human Action claimed that the absence of time preference would lead the consumer to postpone the act of consumption to indefinite future. Olson and Bailey (1981) demonstrated that zero time preference is consistent with positive real interest rate and positive present consumption if the marginal utility of consumption is rapidly decreasing and the income endowment is rising over time.

पThis paper shows that zero time preference does not restrict present consumption to nil even if positive interest rate enables future consumption to be very large. Dynamic neoclassical model is applied to confirm that low intertemporal elasticity of substitution leads to positive present consumption even in the case of patient consumers. Determinants of the optimum present consumption are derived, and it is proved that labour income might not be increasing over time to confirm the approach of Olson and Bailey and to disprove the Mises theory.
\end{abstract}

\section{Keywords:}

time preference, Ludwig von Mises, postponement of consumption, intertemporal elasticity of substitution

JEL Classification: E21, B53, D90 


\section{Introduction}

Ludwig von Mises (1949) in his defence of the pure time preference theory of interest claimed that the existence of zero time preference along with a positive real interest rate would lead the consumer to postpone the act of consumption to indefinite future, which should prove the major statement of the Misesian theory that the time preference must be a priori positive.

Olson and Bailey (1981) suggested that the existence of positive real interest rate might be a direct proof of the positive time preference people have built in their minds. On the other hand, they also demonstrated that zero time preference is consistent with positive real interest rate and positive present consumption if the marginal utility of consumption "drastically" decreases and the labour income endowment is growing over time.

This paper shows that Mises might be wrong. Zero time preference will not block present consumption even if positive interest rate enables future consumption to be very large. A simple neoclassical model is applied to confirm that low intertemporal elasticity of substitution in consumption (drastically diminishing marginal utility) necessitates positive present consumption of patient (i.e. non-impatient) consumers. However, the conclusion of Olson and Bailey (1981) about the increasing labour income is not required. In other words, the Mises theory might be disproved under more relaxed assumptions.

The first section presents the approach of key authors to the possibility of zero time preference and eternal postponement of consumption. The second section elucidates major arguments of Olson and Bailey (1981). Part 3 of this article develops an infinite horizon model of a representative consumer. The model is designed to expose the error in the Mises reasoning. The key conclusion is that under certain conditions, the coexistence of zero time preference with positive real interest rate will not depress present consumption to zero, and the labour income endowment need not be increasing over the planning horizon. In other words, zero time preference does not necessarily lead to an eternal postponement of consumption.

\section{The role of time preference}

Frank Fetter (1915, p. 236) coined the term 'time preference' and criticized BöhmBawerk's third reason of interest, which is based on higher productivity of roundabout methods (Fetter, 1902, p.177). Pure subjective valuations of people between present goods and future goods are at the centre of the Fetter theory.

Fetter also mentioned possibility of zero time preference:

If the needs of men were supplied from day to day by some outside agency, if the things we need fell like manna from the 
skies, ..., there would be no such thing as time-preference or timevalue.

(Fetter 1915, p. 236)

On another occasion, Fetter argued that if man disregarded time differences, i.e. if there was no element of pure time preference, the consumer would spread her income evenly over her lifetime (1915, p. 249).

Ludwig von Mises accepted Fetter's theory of pure time preference. In contrast to Fetter, Mises claimed that time preference of people must be necessarily positive because an acting man a priori prefers satisfaction of the given want earlier rather than later.

Mises tried to prove positive time preference by an indirect proof: the absence of time preference would lead to eternal postponement of the act of consumption.

The very act of gratifying a desire implies that gratification at the present instant is preferred to that at a later instant. He who consumes a nonperishable good instead of postponing consumption for an indefinite later moment thereby reveals a higher valuation of present satisfaction as compared with later satisfaction. If he were not to prefer satisfaction in a nearer period of the future to that in a remoter period, he would never consume and so satisfy wants. He would always accumulate, he would never consume and enjoy. He would not consume today, but he would not consume tomorrow either, as the morrow would confront him with the same alternative.

(Mises, 1949, p.484)

Topan and Păun (2013) remarked that Mises was inconsistent from the pure logic point of view - a general statement may not be negated by another general statement. Hence, the correct negation should be - at least once, man would prefer consumption in the future. Furthermore, Topan and Păun noted that the preference for future would lead to "conscious non-action", which is a logical contradiction. In this respect, they were inspired by Block (1990, p.199) who claimed that the lack of time preference would lead to eternal non-action. Thus, they generalized the idea of Mises of the eternal postponement of consumption.

Murphy (2003) objected that the delay in consumption may, contrary to the views of Mises, expose preference for future satisfaction. Furthermore, saving of a nonperishable good could, according to Murphy, demonstrate the existence of negative time preference. 
A simple two-period neoclassical model can be used to expose the error in the Mises reasoning. As was shown in Potuzak (2016), the absence of pure time preference (the second Böhm-Bawerkian ground for interest) can be reflected in zero subjective discount rate $\rho$ in the standard discounted utility model, where the lifetime utility function $U$ is:

$$
U==u\left(C_{0}\right)+\frac{u\left(C_{1}\right)}{1+\rho}
$$

Marginal utility of consumption is positive but diminishing in every period: $\mathrm{u}^{\prime}>0, \mathrm{u}^{\prime \prime}<$ 0 . As is shown in Figure 1, zero pure time preference $(\rho=0)$ leads to the fact that on the $45^{\circ}$ line the slope of the indifference curve is exactly one in absolute value (Ghez and Becker, 1975). Assuming positive interest rate $(r>0)$, the optimum present consumption is not depressed to zero $\left(C_{0}{ }^{*}>0\right)$. Furthermore, perfect consumption smoothing is not optimal either (point $B$ ), since $r>\rho=0$ (see equation (2)).

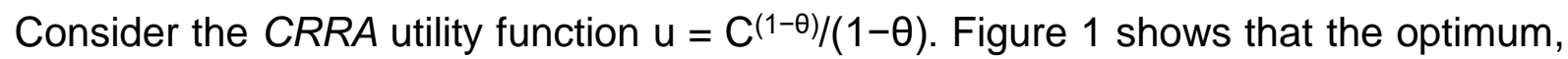
which must obey the Euler equation (2), is not at the terminal point of the budget line $M$, as Mises would predict. ${ }^{1}$

$$
\frac{C_{1}^{*}}{C_{0}^{*}}=\left(\frac{1+r}{1+\rho}\right)^{\frac{1}{\theta}}
$$

It is the law of diminishing marginal utility, which blocks the tendency to postpone consumption of every single good to the future. In the mind of the consumer, wants in the present would be so pressing and future desires (from the present perspective) would be so abundantly satisfied that some goods must be consumed in the present, even when positive interest enables huge consumption in the future and discount of future utilities is absent. Thus at point $\mathrm{E}$, marginal utilities of consumption in each period are not very far off of each other, and wants of similar urgency are satisfied over the lifetime (Hayek, 1927).

\footnotetext{
${ }^{1}$ The income endowment of the consumer is not depicted in Figure 1. It can be point $A, B$, or any point on the budget line AM.
} 


\section{Figure 1: Optimum of a representative consumer with zero time preference}

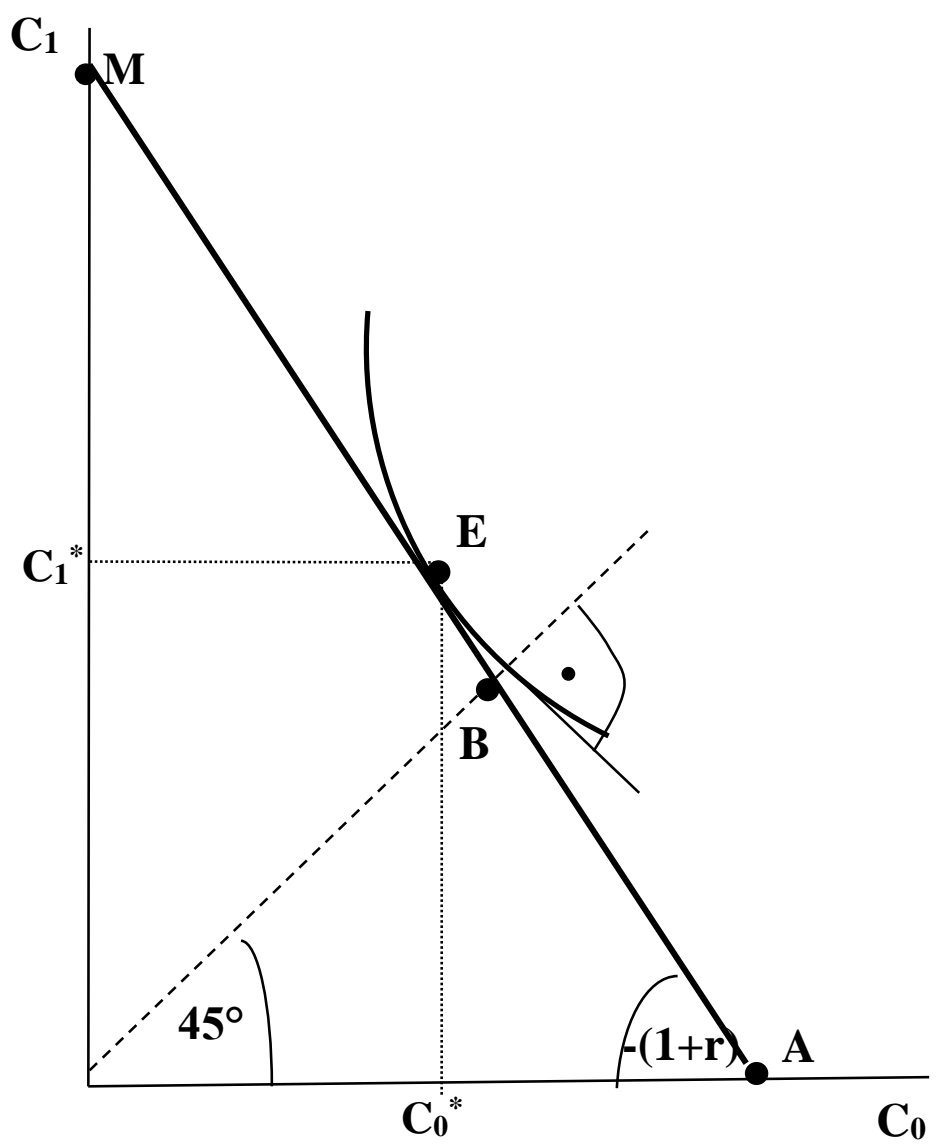

Equation (2) also suggests that low intertemporal elasticity of substitution in consumption (small 1/O), which is consistent with "drastically" diminishing marginal utility (Olson and Bailey, 1981), moves optimal point $E$ further from the Misesian point $M$ and closer to the consumption smoothing point $B$.

The problem with the two period model is that there is an infinite time preference ( $\rho$ $\rightarrow \infty$ ) in all periods following the "death" of the representative consumer (i.e. at $t=2, t$ $=3$, etc.). The consumer may exhibit zero time preference only with respect to one future period. All the other periods are infinitely discounted. Hence, the attack against the Mises theory loses its power because there is an infinite, not zero, time preference in the other periods. As a result, in section 2 the time horizon is extended to infinity in order to reconsider the Misesian argument of the eternal postponement of consumption. 


\section{Eternal postponement of consumption}

We start with an optimal allocation of consumption of a representative individual, who lives for $T$ periods. The lifetime utility function (1) is extended to (3). Her intertemporal budget constraint (IBC) for lifetime $T$ can be represented by (4).

$$
\begin{aligned}
& U=\sum_{t=0}^{T} \frac{u\left(C_{t}\right)}{(1+\rho)^{t}}=u\left(C_{0}\right)+\frac{u\left(C_{1}\right)}{1+\rho}+\frac{u\left(C_{2}\right)}{(1+\rho)^{2}}+\ldots+\frac{u\left(C_{T}\right)}{(1+\rho)^{T}} \\
& C_{0}+\frac{1}{1+r} C_{1}+\frac{1}{(1+r)^{2}} C_{2}+\frac{1}{(1+r)^{3}} C_{3}+\ldots+\frac{1}{(1+r)^{T}} C_{T}= \\
& =Y_{0}+\frac{1}{1+r} Y_{1}+\frac{1}{(1+r)^{2}} Y_{2}+\frac{1}{(1+r)^{3}} Y_{3}+\ldots+\frac{1}{(1+r)^{T}} Y_{T}
\end{aligned}
$$

$Y_{t}$ denotes real labour income at time $t$. Real interest rate $r$ is assumed to be constant over time. One can show that the first order conditions of this problem lead to the following Euler equation for any time $t$ and $t+1$ :

$$
\frac{u^{\prime}\left(C_{t+1}^{*}\right)}{u^{\prime}\left(C_{t}^{*}\right)}=\frac{1+\rho}{1+r}
$$

Equation (5) implicitly defines the optimum path of consumption of a representative individual. Alternatively, the solution of this optimization problem can be expressed as:

$$
\frac{u^{\prime}\left(C_{t}^{*}\right)}{u^{\prime}\left(C_{0}^{*}\right)}=\left(\frac{1+\rho}{1+r}\right)^{t}
$$

Equation (6) can be used to reconsider the Misesian statement that for zero time preference $(\rho=0)$ and a positive interest rate $(r>0)$, an acting man will postpone consumption to an indefinite future. By extending the time horizon to infinity and setting $\rho=0$, we get (Olson and Bailey, 1981, p.12):

$$
\lim _{T \rightarrow \infty} \frac{u^{\prime}\left(C_{T}^{*}\right)}{u^{\prime}\left(C_{0}^{*}\right)}=\lim _{T \rightarrow \infty} \frac{1}{(1+r)^{T}}=0
$$

\footnotetext{
2 This form can be derived by imposing the no-Ponzi-game condition.
} 
Equation (7) suggests that for a positive rate of interest and zero subjective discount rate, the ratio of the marginal utility from consumption in infinity and from consumption today is zero in optimum. This can be achieved either by an infinite marginal utility in the present or zero marginal utility in infinity. If the utility function satisfies usual Inada conditions, infinite marginal utility is achieved for zero consumption, and conversely zero marginal utility is obtained by infinite consumption. Alternatively, if we allow for a subsistence level $C_{\text {min }}$, the infinite $M U$ is reached at this level. Correspondingly, a satiation level $C_{\max }$ would lead to zero $M U$.

Equation (7) therefore requires that in optimum, the present consumption must be depressed to a negligible level unless the budget constraint (4) extended to infinity ( $T$ $\rightarrow \infty$ ) allows for an infinite consumption at $T \rightarrow \infty$ (Olson and Bailey, 1981, p.12). All incomes should be saved to infinity because the compounding of interest in the infinite horizon may expand consumption beyond all limits. Hence, the Misesian analysis might hold in the infinite-horizon model because positive rate of interest seems to be inconsistent with zero time preference. The two-period model obscures this important outcome, and the previous critique of the Mises approach was inaccurate.

Moreover, a positive interest rate and zero subjective discount rate cannot create long-run equilibrium in the production part of the economy if capital exhibits diminishing returns. The never-ending postponement of all consumption implies that people save their entire income. Huge saving and immense accumulation should then extend the capital stock beyond all limits. This process would eventually depress the marginal product of capital to zero along with the interest rate. In the end, the real interest rate and the subjective discount rate must coincide at the zero level, and the accumulation of capital stops.

However, in the real world we usually observe a positive real interest rate. At the same time, we do not witness a radical curtailment of present consumption. For Olson and Bailey (1981), this is an explicit evidence for the existence of positive time preference $(\rho>0)$. As a result, the approach of Olson and Bailey leads to similar conclusions as made by Mises. In equilibrium, the interest rate must be equal to the time preference; otherwise all consumption will be postponed to the infinite future. ${ }^{3}$

The foregoing analysis will become more obvious if we introduce a particular form of the utility function, e.g. CRRA u.f.. Similarly to (2), equation (5) can be represented as:

$$
\frac{C_{t}^{*}}{C_{t+1}^{*}}=\left(\frac{1+\rho}{1+r}\right)^{1 / \theta}
$$

and equation (6) as

\footnotetext{
3 Trostel and Taylor (2001) offered a different explanation for the Euler equation (7) to hold. Consider again the left hand part of equation (7). If tastes of people deteriorate over time, marginal utility in very remote future may converge to zero. Thus, the Euler equation (7) might be satisfied even with finite consumption in the future.
} 


$$
\frac{C_{0}^{*}}{C_{t}^{*}}=\left(\frac{1+\rho}{1+r}\right)^{t / \theta}
$$

As time horizon goes to infinity and for $\rho=0$, (9) yields:

$$
\lim _{T \rightarrow \infty} \frac{C_{0}^{*}}{C_{T}^{*}}=\lim _{T \rightarrow \infty} \frac{1}{(1+r)^{T / \theta}}=0
$$

If the time preference was zero and the real interest rate was positive, the individual would be in optimum either with zero present consumption or with infinite consumption in the infinite future. As a result, it seems that the only stable outcome of this analysis is that the real interest rate is perfectly equal to the subjective discount rate $(r=\rho)$ and the optimum consumption stream is smoothed over time ( $C_{0}$ $\left.=C_{1}=\ldots C_{t}=\ldots\right)$.

However, in the actual world we observe an increasing shape of the consumption profile. In other words, consumption is not constant, as it grows over time at some definite rate that seems to be quite stable in very long periods of time. It can be shown that in standard growth models with labour-augmenting technological progress, consumption (per worker) may grow at the same rate as income (per worker). And this rate is equal to the rate of technological progress $g$ (Acemoglu, 2011).

As a result, the Euler equation (10 or 11) may be consistent (owing to the technological progress) with an infinite consumption in infinity even if present consumption is not depressed to a negligible level. Suppose that the growth rate of consumption (and the technological progress) is $g=2 \%$. For logarithmic utility function $(\theta=1)$, this implies that the difference between the real interest rate and the subjective discount rate is roughly $2 \%$ as well.

It can be shown (using 8) that the optimum growth rate of consumption must approximately obey the following expression:

$$
\frac{\Delta C_{t+1}^{*}}{C_{t}^{*}}=\frac{r-\rho}{\theta}
$$

Thus, if consumption grows at the rate of technological progress $g$ and if this rate is lower than the real interest rate $r$ (which is required for a dynamically efficient economy), ${ }^{4}$ equation (11) (or 8 ) might be satisfied even for a positive real interest rate and zero time preference $(\rho=0)$ if $\theta$ is big enough. This is what Olson and Bailey (1981, p.19) called a "drastically diminishing marginal utility". High $\theta$ is equivalent to a low intertemporal elasticity of substitution in consumption and to a highly curved utility function. For example, if $g=2 \%, r=4 \%$, and $\rho=0 \%$, the only $\theta$ consistent with

\footnotetext{
${ }^{4}$ According to Olson and Bailey (1981, p.19), this seems to be an empirical fact.
} 
equation (11) is equal to 2. Stability in neoclassical models requires $\rho-(1-\theta) g>0$ (Romer, 2006), which confirms the previous calculation.

We demonstrated that the positive interest rate is consistent with zero time preference and non-zero present consumption even in the infinite-horizon model. However, the model requires an exogenous growth in income endowment and sufficiently convex indifference curves (high $\theta$ ). Misesian economists would probably argue that an increasing labour income endowment violates the key assumption of the evenly rotating economy (ERE). It can be replied that such a shape of the income stream is dominant in modern economies, so our model might accurately represent the actual world.

The Misesian argument about the equality of the interest rate $r$ and the time preference $(\rho)$ does not hold, if the time shape of income is increasing. Even if people do not prefer the given satisfaction to be delivered as soon as possible $(\rho=$ 0 ), the real interest rate may be positive, and all consumption will not be postponed to the infinite future.

The economic reason for high $\theta$ and for a positive difference between $r$ and $\rho$, and $r$ and $g$ is as follows. If the income increases over time and people have low intertemporal elasticity of substitution (high $\theta$ ), their preferred profile of consumption is rather smoothed. As a result, they prefer their high future income to be moved closer to present. They do not save very much, which increases the real interest rate both above the subjective discount rate $\rho$, which may be zero, and above the rate of technological progress $g$. It can be shown that on the balanced growth path of the Ramsey-Cass-Koopmans model, the equilibrium real interest rate is $r^{*}=\rho+\theta g$ (Romer, 2006), which confirms the previous statement.

\section{Determinants of the optimum present consumption}

In this section, we derive determinants of the optimal present consumption of an infinitely-lived individual (dynasty). The Euler equation (9) inserted into the IBC (4), extended to the infinite horizon, gives us:

$$
\mathrm{C}_{0}^{*}+\frac{\left(\frac{1+r}{1+\rho}\right)^{1 / \theta} \mathrm{C}_{0}^{*}}{(1+\mathrm{r})}+\frac{\left(\frac{1+r}{1+\rho}\right)^{2 / \theta} \mathrm{C}_{0}^{*}}{(1+\mathrm{r})^{2}}+\ldots=\mathrm{Y}_{0}+\frac{\mathrm{Y}_{1}}{(1+\mathrm{r})}+\frac{\mathrm{Y}_{2}}{(1+\mathrm{r})^{2}}+\ldots
$$

Assume that the (labour) income process is represented by the following difference equation: 


$$
Y_{t}=(1+g) Y_{t-1}
$$

Thus, labour income grows at the exogenous and constant rate $g$ :

$$
Y_{t}=Y_{0}(1+g)^{t}
$$

Substituting (14) into the right-hand side of (12) gives us the present value (PV) of income:

$$
P V_{\text {income }}=Y_{0}+\frac{Y_{0}(1+g)}{1+r}+\frac{Y_{0}(1+g)^{2}}{(1+r)^{2}}+\frac{Y_{0}(1+g)^{3}}{(1+r)^{3}}+\ldots
$$

A simple formula for the sum of the infinite geometric series yields:

$$
\begin{aligned}
& P V_{\text {income }}=Y_{0} \frac{1}{1-\frac{1+g}{1+r}} \\
& P V_{\text {income }}=Y_{0} \frac{1+r}{r-g}
\end{aligned}
$$

A finite $\mathrm{PV}$ in the infinite horizon requires that the interest rate is greater than the growth rate of labour income. This is the condition for a dynamically efficient economy.

The left-hand side of (12) can be written as:

$$
P V_{\text {consumptia }^{*}}=C_{0}^{*}+C_{0}^{*} \frac{(1+r)^{(1-\theta) / \theta}}{(1+\rho)^{1 / \theta}}+C_{0}^{*}\left[\frac{(1+r)^{(1-\theta) / \theta}}{(1+\rho)^{1 / \theta}}\right]^{2}+\ldots
$$

(18) leads to:

$$
\begin{aligned}
P V_{\text {consumptia* }} & =\frac{1}{1-\frac{(1+r)^{(1-\theta) / \theta}}{(1+\rho)^{1 / \theta}}} C_{0}^{*} \\
P V_{\text {consumptia* }} & =\frac{(1+\rho)^{1 / \theta}}{(1+\rho)^{1 / \theta}-(1+r)^{(1-\theta) / \theta}} C_{0}^{*}
\end{aligned}
$$


However, the sum of this infinite series is finite only if:

$$
\begin{aligned}
& (1+r)^{(1-\theta) / \theta}<(1+\rho)^{1 / \theta} \\
& \frac{1-\theta}{\theta} \ln (1+r)<\frac{1}{\theta} \ln (1+\rho)
\end{aligned}
$$

If $r$ and $\rho$ are small numbers, (22) yields:

$$
\begin{aligned}
& 1-\theta<\frac{\rho}{r} \\
& \theta>1-\frac{\rho}{r} \\
& \rho-(1-\theta) r>0
\end{aligned}
$$

Condition (25) shows that zero time preference $(\rho=0)$ is consistent only with $\theta>1$. Values of $\theta$ lower or equal to one would lead to the divergence of the sum of the flow of optimum consumption. (25) also implies that the higher the subjective discount rate (pure time preference), the higher elasticity of substitution (lower $\theta$ ) is feasible to achieve a convergent sum of the flow of consumption.

Using the formula for the present value of income (17), equation (12) can be written as:

$$
\begin{gathered}
C_{0}^{*} \frac{(1+\rho)^{1 / \theta}}{(1+\rho)^{1 / \theta}-(1+r)^{(1-\theta) / \theta}}=Y_{0} \frac{1+r}{r-g} \\
C_{0}^{*}=Y_{0} \frac{1+r}{r-g} \frac{(1+\rho)^{1 / \theta}-(1+r)^{(1-\theta) / \theta}}{(1+\rho)^{1 / \theta}}
\end{gathered}
$$

Using (27) and (9), the level of optimum consumption in any period can be determined. Olson and Bailey suggested that if the time preference is zero $(\rho=0)$, the Euler equation (9) in the infinite horizon implies that present consumption is depressed to zero unless the income endowment grows over time (i.e. $g>0 \%$ ) and the utility function exhibits a drastically decreasing marginal utility $(\theta>1$ in our framework). Our analysis confirms their second observation: $\theta$ must be greater than one to obtain positive $C_{0}{ }^{*}$. However, according to (27), positive $g$ might not be required. 
As can be seen from (27), the condition consistent with positive optimal present consumption is the derived inequality (21). If the time preference was zero $(\rho=0)$, the intertemporal elasticity of substitution must be low $(\theta>1)$, but the growth in labour income $g$ need not be positive, as Olson and Bailey (1981) predicted.

Low elasticity of substitution results in a modest optimum growth rate of consumption that is below the real interest rate. The initial accumulation of assets $\left(\mathrm{C}_{0}{ }^{*}<\mathrm{Y}_{0}\right.$, etc.) then provides enough capital income to finance very high levels of future consumption that will considerably exceed future-period labour income. An increasing profile in labour income is not necessary. A positive difference between the real interest rate and the growth rate in consumption and sufficient saving at the beginning of the planning horizon suffice to generate very high levels of future consumption even without the reduction of present consumption to zero. In other words, the consumer may enjoy future interest income as a source for eternal consumption growth.

The Euler equation (9) or (10) may be used to expose another perspective. Condition (10) requires zero present value of future consumption in the infinite horizon:

$$
\lim _{T \rightarrow \infty} \frac{C_{T}^{*}}{(1+r)^{T}}=\lim _{T \rightarrow \infty} \frac{C_{0}^{*}\left(\frac{1+r}{1+\rho}\right)^{T / \theta}}{(1+r)^{T}}
$$

The PV of $C_{T}$ converges to zero if:

$$
\left(\frac{1+r}{1+\rho}\right)^{1 / \theta}<(1+r)
$$

However, condition (29) leads to (21). With zero time preference, optimal (present) consumption need not be zero; consumption may grow over time, but its growth rate must be lower than the interest rate to depress the present value of future consumption to zero.

The previous analysis examined the optimal behaviour of one representative agent. The case of constant labour income stream of this individual and an increasing path of consumption lead to eternal accumulation of assets owned by this person, which finances the difference between $C_{t}{ }^{*}$ and $Y_{t}$ in more remote future. It is quite difficult to generalize such behaviour for the entire economy. In other words, the constraint for the consumption even of the richest person is the aggregate income in the economy. GDP cannot be constant over time to reach infinite consumption for the given individual. 
From the macroeconomic perspective, the solution of Olson and Bailey (1981), i.e. the uniform growth rate of income and consumption, seems to be reasonable. Let us find the combination of parameters that leads to the equal growth of consumption $\left(x^{*}\right)$ and income $(g)$ :

$$
\begin{aligned}
& 1+x^{*} \equiv \frac{C_{t+1}^{*}}{C_{t}^{*}}=\left(\frac{1+r}{1+\rho}\right)^{1 / \theta}=(1+g) \\
& \frac{1+r}{1+\rho}=(1+g)^{\theta} \\
& r=(1+g)^{\theta}(1+\rho)-1
\end{aligned}
$$

If $r, g$, and $\rho$ are small numbers, (32) might be written as:

$$
r=\rho+\theta \cdot g
$$

Our previous findings are therefore consistent with (33).

Similar results as in (30) can be obtained by focusing on the relationship between optimum present consumption and present income. Present value of the optimum consumption (19) and the definition of the optimum growth rate of consumption $x^{*}$ in (30) imply that:

$$
P V_{\text {consumptia }^{*}}=\frac{1}{1-\frac{1+x^{*}}{1+r}} C_{0}^{*}
$$

Because the PV of income must be equal to the PV of consumption, (34) yields:

$$
P V_{\text {income }}=P V_{\text {consumptia* }}=\frac{1+r}{r-x^{*}} C_{0}^{*}
$$

Using the formula of the present value of income (17), equation (35) might be written as:

$$
\frac{1+r}{r-x^{*}} C_{0}^{*}=Y_{0} \frac{1+r}{r-g}
$$




$$
C_{0}^{*}=Y_{0} \frac{r-x^{*}}{r-g}
$$

As can be seen, the optimum present consumption is below present income when the optimum growth rate of consumption is greater than the exogenous growth rate of income $\left(x^{*}>g\right)$. In this case, the consumer is a saver. On the other hand, it is optimal to be a borrower when the opposite assumption holds. The equality between optimum present consumption $\mathrm{C}_{0}{ }^{*}$ and present income $\mathrm{Y}_{0}$ is consistent with equality between the growth rate of consumption and income $\left(x^{*}=g\right)$. Positive optimum present consumption can be easily derived for the case envisioned by Olson and Bailey (1981), in which the time preference of people is zero $(\rho=0 \%)$, the marginal utility of consumption is "drastically" decreasing $(\theta>1)$, and consumption is growing along with labour income $\left(x^{*}=g\right) .^{5}$

\section{Conclusion}

According to our analysis Mises underestimated the power of the law of diminishing marginal utility in his intertemporal analysis. This law results in the effort to smooth consumption over time and to provide enough consumption goods in every period. Thus, no period can be oversupplied with consumption goods at the expense of other periods even if the time preference is zero and the real interest rate is positive.

We conclude that the Misesian theory holds only under special circumstances characterised by a relatively high elasticity of intertemporal substitution in consumption $(\theta \leq 1)$, i.e. the utility function must exhibit weakly diminishing marginal utility. In such a case, the absence of time preference leads to zero consumption in all periods except for infinity.

Olson and Bailey suggested that in the case of zero time preference the utility function must exhibit "drastically diminishing" marginal utility and income must grow over time. We demonstrated that the path of labour income is quite immaterial provided that its growth rate is lower than the interest rate. In other words, there might exist a consumption path with non-zero present consumption and infinite future consumption that is both consistent with the intertemporal budget constraint and with the Euler equation, notwithstanding the time shape of the labour income stream.

\footnotetext{
${ }^{5}$ In a more complicated dynamic general equilibrium Ramsey-Cass-Koopmans model, the IBC will include initial capital holdings. The representative agent will initially consume part of interest from this capital endowment and (37) will be more complex. On the balance growth path, capital in this economy will grow at the same rate as (both labour and capital) income and consumption. Saving must be therefore positive, growing also at the rate $g$. For example, for the Cobb-Douglas production function with $\alpha=1 / 3$ (and zero depreciation for simplicity) and parameters from the main text, the optimum saving rate will be $s^{*}=16.5 \%$, optimum consumption per effective worker $c^{*}=2.36$, income per effective worker $\mathrm{y}^{*}=2.83$ (which here includes, contrary to the notation in the main text, both types of income), real wage per effective worker $\mathrm{w}^{*}=1.89$, capital per effective worker $\mathrm{k}^{*}=23.33$, and therefore capital income per effective worker $r^{*} . k^{*}=0.04 \times 23.33=0.93=y^{*}-w^{*}$. A more realistic positive depreciation rate of $\delta=5 \%$ leads to $\mathrm{k}^{*} / \mathrm{y}^{*}=3.67, \mathrm{~s}^{*}=25.7 \%, \mathrm{y}^{*}=1.9>\mathrm{c}^{*}=1.41>\mathrm{w}^{*}=1.27$.
} 


\section{REFERENCES}

ACEMOGLU, D. (2011). Introduction to Modern Economic Growth: Parts 1-4 Massachusetts Institute of Technology, 2011.

BLOCK, W. (1990). The DMVP-MVP Controversy: A Note. The Review of Austrian Economics. 1990, Vol. 4, No. 1, pp. 199-207.

FETTER, F. A. (1902). The "Roundabout Process" In the Interest Theory. The Quarterly Journal of Economics. 1902, Vol. 17, No. 1, pp. 163-180.

FETTER, F. A. (1915) Economics, The Century Co., New York, 1915. Reprint 1928.

GHEZ, G. and BECKER, G. S. (1975). A Theory of the Allocation of Time and Goods over the Life Cycle. NBER Chapters. 1975, pp. 1-45. National Bureau of Economic Research.

HAYEK, F. A. von. (1927). On the Problem of the Theory of Interest. In Money, Capital and Fluctuations: Early Essays, ed. McCloughry, R. K. (1984), pp. 55-70. University of Chicago Press.

MISES, L. von. (1949) Human Action: A Treatise on Economics, 4th ed., Fox \& Wilkes, San Francisco, CA. Reprint 1996.

MURPHY, R. P. (2003) Unanticipated Intertemporal Change in Theories of Interest, Ph.D. Dissertation, New York University, 2003.

OLSON, M. AND BAILEY, M. J. (1981). Positive Time Preference. Journal of Political Economy. 1981, Vol. 89, No. 1, pp. 1-25.

POTUŽÁK, P. (2016). Fisher and Mises on Zero Interest: A Reconsideration. Prague Economic Papers. 2016, Vol. 25, No. 2, pp. 203-220.

ROMER, D. (2006). Advanced Macroeconomics, 3rd edition, McGraw - Hill, New York, 2006.

TROSTEL, P. A. and TAYLOR, G. A. (2001). A Theory of Time Preference. Economic Inquiry. 2001, Vol. 39, No. 3, pp. 379-95. 